\title{
LA PRAXIS TEATRAL COMO HERRAMIENTA POLÍTICA PARA LA LUCHA SUBALTERNA. UN ENFOQUE ANTROPOLÓGICO.
}

\author{
Iván Alvarado Castro ${ }^{1}$ \\ Universidad Autónoma de Madrid \\ Gorka Alvarez Barragan² \\ Universidad del País Vasco
}

http://dx.doi.org/10.5209/rev NOMA.2016.v47.n1.52402

Resumen: "El arte por el arte" se nos puede llegar a presentar como uno de los lemas de la desactivación del artista político. El arte teatral de corte político, combatiendo ante la posibilidad de ser fagocitado por el mercado, busca su vía de escape, su resquicio desde donde respirar. Este artículo muestra el teatro como herramienta en la lucha subalterna defendiendo que la práctica teatral, extendida a cualquier persona y engarzada en una visión filosófica concreta, se convierte en un agente de cambio ontológico de sujetos políticos.

Palabras claves: Boal, performance, contrahegemonia y subalternidad.

Abstract: "Art for art's sake" could be seen as one of the slogans for political artist deactivation. Political theater, struggling against the possibility of being absorbed by the market, tries to find its way of escape, its little hole from where taking breath. This article shows theater as a subaltern tool for fighting and mantains that theater trainining and playing, extended to anyone and linked to a concrete philosophical view, becomes to an ontological agent of change of political subjects.

Keywords: Boal, performance, contrahegemony and subalternity.

\footnotetext{
${ }^{1}$ Iván Alvarado Castro es licenciado en historia por la Universidad de Las Palmas de Gran Canaria, licenciado en antropología por la Universidad Autónoma de Madrid, Diplomado en Arte Dramático por la escuela de teatro Cuarta Pared. Es además miembro del Dpto. de Antropología social y cultural de la Universidad Autónoma de Madrid en calidad de personal investigador en formación y colaborador del Instituto universitario de migraciones desarrollo y etnicidad (IMEDES).

${ }^{2}$ Gorka Alvarez Barragan es Ingeniero en Informática por la Universidad de Mondragón, graduado en Antropología Social y Cultural por la UPV/EHU y alumno del Máster en Antropología Social y Cultural de la UPV/EHU, está formado en Arte Dramático por el TAE Donostia. Además es miembro de Gizat, Grupo de Teatro de las Oprimidas de Donostia-San Sebastián.
} 


\section{Introducción}

Ubicando la práctica teatral en el centro mismo de nuestra investigación, el presente artículo muestra el potencial político y transformador que yace en los procesos de creación de dicha disciplina. Nos apoyaremos tanto en investigadores e investigadoras teatrales como en teóricos y teóricas sociales que desde sus propuestas hacen emerger lo político.

La visión de autores como César de Vicente (Vicente de, 2013) que cuestionan el desgaje de la política del campo artístico y los motivos que existen tras ello, nos guía a poner el foco en la visión de Bourdieu, tal y como recoge Méndez, de los sistemas sociales como sistemas:

"[...] de desigualdad, fuerza y dominación, que tienen poderosos efectos sobre acontecimientos y actos humanos, y que restringen posibilidades de acción de sujetos marcados por su sexo, raza, clase o pertenencia étnica. Esas marcas sirven para atribuirles una naturaleza, un estatus, unas posibilidades, una posición en el espacio social". (Méndez, 2009:97).

Una propuesta clara que une lo político y el teatro viene de Brasil, de la mano del dramaturgo y director de teatro brasileño, Augusto Boal. Éste hace emerger el potencial político con su propuesta del Teatro del Oprimido consistente en:

"Un sistema de ejercicios físicos, juegos estéticos y técnicas especiales cuyo objetivo es restaurar y restituir a su justo valor esa vocación humana, que hace de la actividad teatral un instrumento eficaz para la comprensión y la búsqueda de soluciones a problemas sociales e intersubjetivos". (Boal, 2004: 28).

La propuesta de Boal trabaja siempre con situaciones de: "opresión que se dan siempre que alguien utiliza el poder que le da la fuerza o su estatuto social, económico, o incluso cultural, para reducir a alguien a la pasividad, sumisión, a la condición de objeto" (Boal, 2001:188).

Podemos decir que Boal respondió con su propuesta a la pregunta clave que, según el investigador del teatro político César de Vicente, ha de responder todo Teatro Político: "¿Cuál es la estructura de poder que determina las condiciones sociales en las que suceden los hechos?" (De Vicente, 2013:16).

Pero en nuestra búsqueda de elementos articuladores entre el teatro y lo político encontramos otra propuesta sugerente. La filósofa y teórica del género Judith Butler reflexiona sobre la dificultad de dirimir las líneas divisorias entre: "el papel teatral y el papel social" (Butler, 1988: 308), si bien ve una mayor permisividad social en lo que ocurre en el escenario que en lo que ocurre en la calle: "Desde luego, la vista de un travesti en el escenario puede provocar placer y aplausos, mientras que la vista del mismo travesti al lado de nuestro asiento en el autobús, puede provocar miedo, ira, hasta violencia" (ibid.).

La performance fuera de contexto inquieta. En este caso inquieta porque lo que en el teatro no es más que actuación, en la calle ya no está la convención teatral, se rompe la membrana que separa el escenario de la vida. La performance pasa de ser un espectáculo mediado por la concepción de lo teatral a ser un acto realizativo, un acto que constituye a un sujeto y que impregna lo social. El individuo y lo social construido a través de actos, de 
performances constitutivas (ibid.: 297). Es ésta una visión desarrollada por los denominados performance studies.

\section{De la cultura como texto a la cultura como acto}

La clave fundamental de los performance studies está en el paso de entender la cultura como texto (Geertz, 2011: 372) a entenderla como performance (Fischer-Lichte, 2010: 53). Victor Turner, Erwin Goffman o Judit Butler son autores que se relacionan, de maneras diversas, con esta visión de la cultura.

A modo de resumen podemos decir que Turner analiza el ritual como una escena teatral denominando a los momentos de conflicto que urgen durante la interacción social cotidiana drama social (Sánchez-Prieto, 2013: 79-80), mientras que Goffman utiliza la metáfora teatral directamente en la vida cotidiana enfatizando: "el carácter estratégico y maquiavélico de la vida social, centrándose en el modo en que los individuos crean y negocian su imagen" (Ibid:: 80). Por último Butler, aplicando la performatividad a cómo nos construimos como hombres o mujeres, define el género como: "un acto, una identidad temporalmente instituida por una repetición de actos discontinuos, una identidad construida, una performance social sostenida" (ibid.: 78-79). El sociólogo Jeffrey Alexander, situado también dentro de los performance studies, iguala el objetivo de la representación escénica con el de la representación social:

"El objetivo de la actuación secular, bien sea en un escenario o en la sociedad, sigue siendo, al igual que la ambición del ritual sagrado: la identificación psicológica y la extensión cultural. El propósito es crear mediante la actuación profesional y convincente, la identificación psicológica de la audiencia con el actor y el texto, y de esa manera lograr la proyección del significado cultural de la actuación a la audiencia." (Alexander, 2005:31).

Volvamos al giro en el enfoque del género de Butler. Encontramos que son los actos performativos, (realizativos en castellanizado) los que constituyen el género. Butler está reflejando cómo la historia del género se inscribe en el cuerpo y se reproduce desde éste a través de la prácticas, a través de las performances cotidianas. La autora nos señala su potencial político con el ejemplo del travesti ya que éste, fuera del escenario, no cumple la norma hegemónica sobre el cuerpo generizado. Se muestra así la reflexión y el ensayo teatral como proceso político hacia la ruptura de la frontera entre el escenario y la calle, pasando de un teatro-espectáculo a un teatro-ensayo. O recogiendo las palabras de Boal: "un ensayo para la revolución" (Boal, 2009: 47).

Una historia clave en la progresión de Boal es la que vive con un campesino llamado Virgilio (Boal, 2004: 12-15). Tras una actuación, en la cual se habla de la toma de tierras, Virgilio se le acerca y le dice que entre los fusiles de la escena y los que ellos tienen en el pueblo pueden ir a casa del hacendado y decirle que les devuelvan sus tierras. Cuando Boal le cuenta que él y su grupo son sólo actores y que los fusiles no son de verdad, Virgilio comprende que la sangre que en la escena proponían derramar no era la de los actores sino la de los campesinos. Virgilio se siente engañado y Boal comprende que sólo se hará 
teatro si se corren los mismos riesgos que los personajes que interpretan. Esto con el fin de evitar lo que posteriormente denominó: "Síndrome del Che Guevara" (Boal en Abellán 2001: 182) que se basa en ir a un sitio y decirle a otro qué debe hacer.

Boal, influido en la obra de Paulo Freire, evita toda jerarquía pedagógica. Trabaja con el material, las opresiones y las condiciones del colectivo que trabaja desde el Teatro del Oprimido. Evita también un trabajo desde lo imaginativo sin tener en cuenta las relaciones de poder y las opresiones que atraviesan al colectivo. De aquí que veamos un distanciamiento, tanto de Boal como de Butler, con lo que Shechner, denomina "conducta restaurada", la cual es la característica central de la performance:

"[...] la conducta restaurada es "yo portándome como si fuera otro" o "como si estuviera fuera de mi", o "yo como si no fuera yo mismo", como en trance. Pero ese "otro" puede también ser "yo sintiéndome o siendo de otro modo [...]". (2000: 109).

Tanto Boal como Butler trabajan desde el contexto, desde lo histórico, desde la circunstancia concreta hacia el cambio en lo político. Boal, por ejemplo, se apoya en la posibilidad de abordar situaciones de opresión, de ensayarlas, trabajando desde el teatro en busca de unos cambios sociales determinados. Lo posible que se da en el ensayo está enraizado en la circunstancia, en las relaciones de poder que permean la vida de los y las protagonistas, por tanto se aborda del conflicto desde las propias opresiones del grupo y no de otro.

La obra de Boal- que auna filosofía, estética, técnica y política- enlaza con la subalternidad al intentar dar al pueblo un papel protagónico (Boal en Abellan, 2001: 157) realizando un teatro que cambie la realidad.

Si para Boal la historia que tuvo con Virgilio marcó su trayectoria, no menos valor le da a la que originó el teatro foro, una pieza teatral abierta a la participación y acción creativa del público:

"En este nuevo género, el debate no acontece al final: el foro es el espectáculo, el encuentro entre los espectadores, que defienden sus ideas, y los actores, que contraponen las suyas. En cierto modo, es una profanación: se profana la escena, altar donde, normalmente, sólo los actores tienen derecho a oficiar. Se destruye la obra propuesta por los artistas para construir otra todos juntos. Teatro no didáctico, según la antigua acepción del término, sino pedagógico, en el sentido de aprendizaje colectivo". (Boal, 2004: 20).

El teatro foro nace en Perú en 1973, de la experiencia de una mujer que ante una obra de maltrato no se queda indiferente y le grita a la actriz desde el público que debía actuar de modo distinto. La actriz hace caso a la mujer tras la aceptación de Boal a hacer la acción y es más severa con su pareja en escena. Pero la mujer vuelve a increparla ante lo cual la actriz vuelve a ceder ante las pretensiones de la mujer. A la tercera, suele ir la vencida dicen, pero la mujer del público tampoco lo ve factible ante lo cual Boal le dice que suba ella y lo haga. La mujer sube al escenario y cuando le toca actuar lo que hace en vez de seguir la lógica de la actriz golpea al actor y lo manda a hacer la cena. Se pasó de preguntar al público "¿qué hacer?" a que fuera el propio público quien 
actuara la solución. Una solución no sólo teórica sino también práctica, una solución basada en la praxis.

Hacemos un breve inciso para definir praxis. Nos amparamos en la definición que da el político y filosofo italiano Antonio Gramsci:

"[...] se llega incluso a la igualdad o ecuación entre "filosofía y política", entre pensamiento y acción, es decir, a una filosofía de la praxis. Todo es político, incluso la filosofía o las filosofías, y la única filosofía es la historia en acto, es decir, la vida misma." (Gramsci, 1970: 29).

Es por dicho motivo por el cual consideramos más apropiado hablar de praxis teatral que de teatro cuando nos referimos a la obra de Augusto Boal.

El teatro foro es un claro ejemplo de praxis teatral. Recupera la palabra foro como diálogo pero la recupera para dialogar durante el espectáculo. El público puede parar la escena e intervenir. El espectador se convierte en espectactor. Boal diseña un modelo de técnicas diferentes para crear un teatro donde actor y público se transformasen mediante la praxis que les acontece en el mismo mundo.

Esto supone un cambio respecto a la postura de los autores alemanes de la primera mitad del s.XX: Erwin Piscator y Bertolt Brecht. La diferencia entre el teatro político creado en Alemania y el nacido en Brasil radica en que uno es un teatro intelectual donde el actor y la actriz dan un mensaje trabajado y el otro está más centrado en la pedagogía de la vivencia.

Brecht es insuficiente para Boal. Brecht concibió en la dramaturgia y en el trabajo del actor los mecanismos para imposibilitar la identificación aristotélica, para que el espectador pensase la escena e hiciese un juicio de valor sobre la misma, donde la emoción no le cegara sino que lo motivara a actuar (Barauna, 2009: 59). Pero para Boal no bastaba sólo pensar, había que actuar también, lo que no excluye pensar. Es decir, no se limita al acto intelectual sino que engarza a éste en la acción, integrando, desde nuestro enfoque, el legado de la filosofía de la praxis de Gramsci.

Veamos en el siguiente cuadro qué diferencias esenciales hay entre Aristóteles, Brecht (y Piscator) y Boal:

\begin{tabular}{|l|l|l|}
\hline Aristóteles & \multicolumn{1}{|c|}{ Brecht/Piscator } & Boal \\
\hline $\begin{array}{l}\text { Escenario encarna } \\
\text { suceso }\end{array}$ & $\begin{array}{l}\text { Escenario cuenta } \\
\text { suceso }\end{array}$ & $\begin{array}{l}\text { Escenario se confunde } \\
\text { con la realidad, a veces } \\
\text { se inserta en ella }\end{array}$ \\
\hline Consume la actividad & Despierta la actividad & Hace actividad \\
\hline Le procura vivencias & Le procura conocimiento & Le procura experiencias \\
\hline
\end{tabular}


Nómadas. Revista Crítica de Ciencias Sociales y Jurídicas | 47 (2016.1)

\begin{tabular}{|l|l|l|}
\hline $\begin{array}{l}\text { El espectador es } \\
\text { implicado en una acción }\end{array}$ & $\begin{array}{l}\text { El espectador es } \\
\text { confrontado con ella }\end{array}$ & $\begin{array}{l}\text { El espectador es } \\
\text { espectactor }\end{array}$ \\
\hline $\begin{array}{l}\text { La persona se presenta } \\
\text { como algo conocido } \\
\text { análisis }\end{array}$ & $\begin{array}{l}\text { La persona es objeto de } \\
\text { La persona de la } \\
\text { misma onádisis insertándola en } \\
\text { la historia }\end{array}$ \\
\hline $\begin{array}{l}\text { Lo que la persona debe } \\
\text { hacer }\end{array}$ & Lo que puede hacer & Lo que la persona hace \\
\hline $\begin{array}{l}\text { Comunicación } \\
\text { unidireccional }\end{array}$ & $\begin{array}{l}\text { Comunicación } \\
\text { unidireccional }\end{array}$ & $\begin{array}{l}\text { Comunicación } \\
\text { bidireccional }\end{array}$ \\
\hline
\end{tabular}

De Aristóteles a Boal. Fuente: Brecht 2004 y Baraúna 2009. Elaboración: Propia.

En el viejo continente, el arte de Boal pasa a ser muy cotizado, reside en países como Portugal o Francia moviéndose por el continente enseñando su técnica teatral. La cuestión reside para Boal, en estos años, en cómo desarrollar un método de lucha subalterna desde el teatro en Europa donde la violencia directa es transformada en violencia simbólica, donde el primer enemigo para la lucha es uno mismo pues el europeo y la europea tienen "el poli en la cabeza" (Boal, 2004: 21), esto quiere decir que tiene la opresión incorporada.

Esta idea no es nueva, si nos acercamos a una de las obras clave de los teóricos postestructuralistas como es Anti-Edipo, lo que apunta directamente Michel Foucault en el prólogo es que dicha obra ataca frontalmente al fascimo, pero no sólo el histórico, como el que pudo vivir Boal en su periplo por América Latina, sino: "el fascismo que se halla dentro de nosotros, que acosa nuestras mentes y nuestras conductas cotidianas, el fascismo que nos hace amar el poder, desear aquello mismo que nos domina y explota" (Foucault, 1994: 2-3).

El juego que proponemos, apoyándonos en los referentes teóricos trabajados, es un juego de afuera hacia adentro y de adentro hacia afuera. Es decir, un trabajo hacia la concientización de las condiciones de poder que nos atraviesan y nos conforman para trabajar sobre ellas y actúar en lo político, transformando las relaciones de poder que articulan lo social.

Trabajo de tal magnitud requiere de tiempo y esfuerzo que ubicamos en el proceso de entrenamiento y creación teatral. Es a través de éste proceso desde dónde opera la transformación de los sujetos y de los colectivos. Defendemos así la visión de un arte para ser vivido frente a la de un arte para ser contemplado. Un arte concebido desde su valor de uso como propone Debord (Debord, 2009: 13).

Vemos así el arte teatral como una herramienta para reflexionarse y hacerse, en definitiva, como una tecnología del yo: 
"[...] que permite a los individuos efectuar, por cuenta propia o con la ayuda de otros, cierto número de operaciones sobre su cuerpo y su alma, [...] obteniendo así una transformación de sí mismos con el fin de alcanzar cierto estado de felicidad, pureza, sabiduría o inmortalidad". (Foucault, 2010: 48).

En esta última etapa de su obra Foucault pone su mirada en las formas de resistencia ante el poder que despliega el sujeto. Un sujeto que el propio Foucault había hecho desaparecer entre las estructuras de poder- en sus trabajos sobre la genealogía del saber y del poder- y que hace reaparecer a partir del análisis de las prácticas del sí. Para este último Foucault, estas prácticas materializan una ética del yo indispensable como resistencia al poder político (Foucault, 2005: 240).

Foucault relaciona el gnothi seauton (conócete a ti mismo) dentro del marco más general de la epimeleia heautuo (inquietud de sí mismo) como: "[...] una de las formas, una de las consecuencias, una suerte de aplicación concreta, precisa y particular, de la regla general: debes ocuparte de ti mismo, no tienes que olvidarte de ti mismo, es preciso que te cuides". (Foucault, 2005: 17-18).

Elige la figura de Sócrates y sus enseñanzas a Alcíbiades para desarrollar tales preceptos. Sócrates incita a los demás a ocuparse de sí mismos, lo hace olvidándose de sí mismo y dando a la epimeleia heautuo (inquietud de sí mismo) la categoría de despertar: "La inquietud de sí mismo [...] es un principio de agitación, un principio de movimiento, un principio de desasosiego permanente a lo largo de la vida" (ibid.: 21-22). Por ello las categorías que aparecen en la inquietud de sí son: a) Un cambio respecto a la actitud con el mundo; b) Una determinada forma de mirada y c) Acciones que se desarrollan sobre uno mismo (Ibíd.: 26).

Es sumamente interesante todo este desarrollo porque en estos preceptos nos encontramos con un cambio en la relación con respecto al mundo y un cambio que se debe desarrollar para toda la vida (Foucault, 1999: 278). Supone un nuevo modo de vivir que se incorpora no sólo a base de aprender sino también de desaprender. Al convertirse la práctica del sí en una práctica adulta, poco a poco la función pedagógica va dejando paso a otras funciones:

" [...] La práctica de sí ha de permitir deshacerse de todas las malas costumbres, de todas las falsas opiniones que se pueden recibir del vulgo, o de los malos maestros [...] desaprender (de-discere) es una de las tareas importantes del cultivo de sí. [...] pero tienen también una función de lucha. La práctica de sí es concebida como un combate permanente [...] pero sobre todo, este cultivo de sí tiene una función curativa y terapéutica, se encuentra más próxima al modelo médico que al modelo pedagógico". (Foucault, 1999: 279280).

Esto conlleva una serie de ejercicios que pueden ser de cualquier disciplina y por ende, como es el caso, pueden ser propios de la praxis teatral.

Nos referimos a que si cambiamos la mirada de la praxis teatral desde el modo de hacer al modo de hacerse podremos encontrar el cambio de paradigma desde la hermenéutica del texto a la del sujeto. Este encuadre teórico sólo es posible si damos la importancia que merece al proceso vivido, al proceso de 
subjetivación, en este caso subjetivación política desde ejercicios de praxis teatral.

El énfasis en la importancia del proceso de entrenamiento y creación teatral nos lleva a preguntarnos sobre el colectivo que se sumerge en este proceso. Esta cuestión nos lleva hacia la communitas.

\section{El colectivo teatral: ¿communitas?}

Para Schechner los grupos que hacen teatro viven situaciones "liminoides" (Schechner, 2000: 87), haciendo una lectura desde Turner, el cual ha tomado el término a Van Gennep. Lo liminal, proveniente de limen- frontera-, es el lugar no clasificado donde una persona está fuera de la sociedad, donde no tiene status y conlleva una obligatoriedad en la acatación de las normas de ese estado. En contrapartida a lo liminal, lo liminoide es una característica típica de las sociedades post-industriales, proviene del griego "eidos" forma, es el lugar del juego, el lugar de la creatividad, donde nace la antiestructura (Turner, 1982: 32-33), es decir, donde se rompen el sistema de relaciones, jerarquías y status sociales.

Sus miembros están en un periodo liminoide: no tienen posiciones asignadas y desarrollan una intensa camaradería o igualitarismo interno desapareciendo, en un principio, los status, formándose así un grupo que ha de gestionar sus relaciones internas. Respecto a este proceso del colectivo nos gustaría plantear ciertas cuestiones que no abordaremos en este artículo: ¿En qué medida influye la autogestión del colectivo y las relaciones personales que nacen en éste en la activación política? ¿Y en la continuidad del proyecto? ¿Cómo se gestionan las diferentes capacidades, modos de operar y de sentir dentro del grupo? Por el hecho de que no exista una estructura previa en las relaciones no significa que no se genere una nueva que establezca un nuevo mapa de poder.

Turner establece que la communitas no puede ser individual si quiere satisfacer las necesidades materiales y organizativas de los seres humanos (Turner, 1988: 135). El autor apunta que algunas de éstas communitas pueden llegar a tener un carácter revolucionario. Por lo tanto, si una communitas es un grupo que se enfrenta a la hegemonía deberá tener una serie de premisas muy claras, un proyecto distinto al que ofrece la hegemonía.

Con tal afirmación no defendemos que todo proceso de subjetivación sea liberador, como apuntan Foucault (1999: 204-206) o Guattari (1992: 12) al identificar en el caso del Irán de Jomeini procesos de subjetivación política focalizada en: "arcaísmos religiosos y en actitudes sociales globalmente conservadoras, particularmente en lo que se refiere a la condición femenina"(Ibíd.).

Sin embargo es interesante atender a los rasgos de estos grupos y entender sus posibilidades de lucha ante la hegemonía. Para ello antes que nada hemos de decir qué entendemos por hegemonía.

El concepto que manejamos es, nuevamente, de Antonio Gramsci. Para el político italiano la hegemonía parlamentaria es una combinación de consenso y 
de fuerza que se equilibran sin que la fuerza supere demasiado al consenso, sino que más bien parezca apoyada por la mayoría gracias a los órganos de opinión pública (Gramsci, 1981: 123).

Por tanto no podemos disociar el consenso de la fuerza para el concepto de hegemonía planteado, lo cual nos lleva a pensar cómo se consigue dicho consenso. Para Gramsci se basa en la producción de una concepción general de la vida (una filosofía) y un programa escolástico que se desarrolle desde una facción homogénea.

De ahí la importancia que da Gramsci a los aspectos culturales en sus Cuadernos de la cárcel siendo de vital importancia generar una Contrahegemonía, esto es: "producir una interpretación coherente del mundo en que el que viven susceptible de cuestionar las interpretaciones hegemónicas existentes de una forma efectiva" (Crehan, 2004: 126. Cursiva de la autora).

Cuando Crehan habla de efectiva no está negando que para Gramsci el subalterno tenga una visión del mundo propia, sólo que al ser contradictoria y fragmentada es inoperante para la lucha.

Para nosotros entender este proceso de construcción es de vital importancia para entender nuestro objeto de estudio porque los interrogantes que se nos plantean son varios ¿Puede dicha construcción ser realmente unitaria? ¿Qué papel juegan las relaciones de poder internas del grupo para dicha construcción?

Por eso nos resulta de vital importancia entender las características de communitas que guardan los grupos teatrales como puede ser la creación de grupo frente a la realidad social, el espacio de la posibilidad frente a lo prohibido o lo normativo o el espacio de la camaradería.

Aunque si bien el grupo teatral guarda relaciones con la communitas no puede entenderse directamente como tal ya que no atiende a las características de una institución total (Goffman, 1987), es decir, una institución donde el sujeto sufre una mutilación de su yo al cortar relaciones con el mundo exterior.

Para nosotros estaría más cerca del concepto de lugar islote del sociólogo Löic Wacquant (Wacquant, 2004: 40). Las personas pueden acudir a ese islote y luego volver a vivir dentro de la hegemonía. Esto se da sobre todo en grupos que realizan actos liminoides, grupos que se unen para trabajar desde la praxis teatral en determinados lugares y que luego vuelven a su vida cotidiana hasta la siguiente reunión o ensayo.

En el caso de grupos subalternos que hagan teatro encontramos en Schechner una etiqueta adecuada: "Grupos de Entrenamiento Intercultural" (Schechner, 1989: 229). Sus funciones son:

1. Interpretar un texto dramático o texto de performance.

2. Transmisión de un texto performativo.

3. Transmisión de secretos de performance.

4. Expresión propia.

5. Aprender una técnica específica. 
6. Formación de grupo.

Pasaremos a explicarlas una a una pues son las bases para entender posteriormente la metodología de trabajo que siguen estos grupos y conectar con el trabajo de James $\mathrm{C}$. Scott y la inmersión en lugares donde se cuece la contrahegemonía, donde se genera un discurso oculto que se prepara para salir a la "escena". El apoyo para estas explicaciones en (Schechner en Barba, 1990: 330-331).

\section{Interpretar un texto dramático o performance}

Esto es la característica principal del entrenamiento. Este grupo hace algo que no es suyo propio sino transmitido. Por eso debe entrenar para transmitir algo que puede haber creado él a partir de algo que les han enseñado. Asunto éste que liga con la segunda característica.

\section{Transmisión de un texto performativo}

Esto no quiere decir que el texto sea sólo escrito. Puede haber partes más corporales donde las hexis (acción corporal) digan más que el texto escrito. La cuestión está en el maestro que lo transmite pues aquí reside uno de los peligros de este tipo de grupo ya que: “...deben tener un mínimo de concordancia entre el habitus de los agentes movilizadores (profeta, líder) y las disposiciones de aquellos que se reconocen en sus prácticas..." (Bourdieu, 2007: 96). El peligro reside en que este grupo se puede convertir en un reproductor de las teorías de un líder. De ahí la importancia de identificar las características de la figura del maestro, si existe, de modo que nos pueda ayudar a comprender si el proceso creativo es grupal o meramente reproductor de la voluntad del maestro.

Autoras como Verenna Daas, basándose en Sumit Sakar, hablan del proceso de construcción del líder carismático (Daas, 1997: 289) el cual pasa por tres grados: a) Reconocimiento como avatar, un ser con poderes extraordinarios. b) Conferir inmunidad a sus seguidores y c) Se llama a la transformación social del mundo.

Quizá la definición más correcta sea la de personaje faro (Bourdieu, 2007: 53), como metáfora del maestro que alumbra a su alumnado por un camino donde se aprende una técnica, pero realmente es mucho más que eso.

Es el propio Bourdieu quien aborda esta cuestión de modo, a nuestro entender, de modo magistral, cuando compara los procesos de creación artística con la magia (Bourdieu, 1977). Para dicho autor no se puede entender el proceso de creación mágica sin entender que la creencia colectiva se fundamenta más bien en el desconocimiento colectivo que es el que infunde de poder al mago (Bourdieu, 1977: 13) calificando la producción de la obra de arte como producto de una: "inmensa empresa de alguimia social" (ibid.: 14).

No obstante, se pueden dar casos de grupos de creación colectiva, en dicho caso el proceso de trabajo difiere principalmente en que no existe la figura central del maestro sino que el proceso de trabajo es dividido entre los 
integrantes del mismo. Los procesos de creación colectiva se componen de diferentes partes: a) Dramaturgia colectiva, b) nuevos códigos y renovación lenguaje escénico, c) noción de grupo, d) actor múltiple, e) mayor conciencia de papel social y f) teatro dentro de la cultura nacional. (Rubio, 2001: 32).

Estos nuevos conceptos se dividen en tres partes, de un lado el proceso de acumulación sensible que es equipara con el mito y de otro el trabajo de mesa que es equiparado con la ciencia (ibid.: 99) el cual ve el resultado en el tercer momento que es el de la puesta de escena, llamado trabajo de sala (ibid.: 77).

Para Rubio es preciso hablar de teatro integral (ibid.: 124) porque aborda un ser humano integral dentro del grupo.

Pese a ser colectivos donde la figura del maestro se disipa la figura del grupo sigue siendo plenamente importante con lo cual ambos procesos, tanto si tienen una figura de maestro presente como si es un trabajo grupal son válidos para nuestro objeto de estudio al tener el grupo una vertebración central en el proceso.

\section{Transmisión de secretos de performance}

Generalmente este tipos de performances van muy ligadas a un secreto que se transmite de familia en familia o en grupos cerrados, esto va muy ligado a los propio circuitos de producción del conocimiento que o bien van centralizados en la figura de un único maestro, como hemos apuntado o que pueden ser desarrollados por estructuras de conocimientos globalizadas como es el caso de los Grupos de Teatro del Oprimido que se ubican por todo el mundo.

\section{Expresión propia}

El trabajo de los performers es alcanzar un grado de expresión personal en la cual se de una correlación entre forma y contenido, donde lo subjetivo pueda verse objetivado por los usos corporales de determinados capitales. Si en un gimnasio de boxeo los boxeadores entrenan de determinado modo y cuidan sus dietas y hábitos personales para conseguir un determinado objetivo sobre el ring, esto es, cuidan de sus capitales corporales (Wacquant, 2004), en un proceso de entrenamiento intercultural, como el que estamos abordando en este caso, aprenden unas técnicas específicas para que su forma y el contenido de la misma tenga un significado determinado y no otro.

\section{Aprender una técnica específica (Schechner, 2007: 229)}

Cada grupo aprende una técnica específica que le es distintiva. En el campo teatral no es lo mismo aprender el método del primer Stanislavski que del último o aprender el método de Grotowski. Si el grupo hace además un teatro político, el motivo por el cual hacen teatro no será el mismo. Su objetivo puede no ser hacer arte por arte sino transmitir un determinado mensaje el cual no llegará igual de un modo que de otro. 


\section{Formación de grupo}

Es imprescindible conseguir esta premisa para poder desarrollar las anteriores. Hay dos tipos de grupos de entrenamiento intercultural (Schechener en Barba, 1990: 331) por un lado, en la cultura euroamericana, el grupo se conforma en contra de la corriente más importante, mientras que por otro, en las culturas de espectáculos colectivos, el grupo pertenece a la corriente principal.

Estos grupos tienen determinadas expresiones que adquieren valor ontológico (Turner, 1988: 110) y que moldean al neófito además de dar sentido a las relaciones internas, lo que nos da un distintivo del grupo pues va conformando lo que Geertz denomina la cosmovisión del grupo (Geertz, 2000). El término cosmovisión es un término complejo. Un autor que lo ha abordado desde la antropología, íntimamente ligado al de ethos, es Clifford Geertz:

"El ethos de un pueblo es el tono, el carácter y la calidad de su vida, su estilo moral y estético, la disposición de su ánimo; [...]. Su cosmovisión es su retrato de la manera en que las cosas son en su pura efectividad; es su concepción de la naturaleza, de la persona, de la sociedad. La cosmovisión contiene las ideas más generales de orden de ese pueblo... el ethos se hace intelectualmente razonable al mostrarse que representa un estilo de vida implícito por el estado de cosas que la cosmovisión describe, y la cosmovisión se hace emocionalmente aceptable al ser presentada como una imagen del estado real de cosas del cual aquel estilo de vida es una auténtica expresión" (Geertz, 2000: 118)

La definición dada por Geertz de cosmovisión es, cuanto menos, peligrosa por dos motivos. El primero de ellos es que da una visión de la cultura homogénea. La cultura puede ser muchas cosas pero jamás es homogénea, aunque ésa sea una de sus aplicaciones más corrientes cuando recurrimos al sentido común, a la argumentación: "eso siempre ha sido así". El segundo, que explica la cosmovisión desde lo que cataloga como "representaciones culturales" (Geertz, 2000: 108), como un todo acabado, como si la cultura fuese una foto fija en el tiempo.

Es difícil explicar una categoría como cosmovisión desde la representación, sin atender a la gestación de la misma dentro de un proceso y un contexto, algo que proponen autores como Bharucha (2005: 1, 32) o Alvarado (2013: 92).

Más interesante, desde mi punto de vista, es el caso de Augusto Boal, el cual se acerca a este término desde un modo más práctico:

"En Lima también se preguntó a la gente qué era la explotación. Muchas fotos mostraban al dueño de la tienda; otras, el cobrador del alquiler; algunas a una oficina pública... un niño respondió con la foto de un clavo en la pared. Para él ese clavo era el símbolo más perfecto de la explotación. Pocos lo entendieron, pero todos los demás niños estaban perfectamente de acuerdo y conformes en que la foto expresaba lo que sentían frente a la explotación." (Boal, 1982: 21).

Con este pasaje queda claro que una situación de explotación sufrida por muchos no es igual para todos. El clavo es la señal que los niños lustradores de botas, de las barriadas de Lima, daban a la persona que les guardaba el equipo en la noche para no cargar con él hasta sus casas, sus compañeros adultos no entendían el símbolo de la explotación de sus hijos, Boal expone 
claramente en este caso cómo los niños sí tenían una cosmovisión como grupo social pero no compartida con los mayores.

Entendemos cosmovisión como el modo compartido de mirar y de interpretar la realidad por un grupo. Esta cosmovisión tiene carácter dinámico, en contraposición con la foto fija que defiende Geertz.

\section{La Subalternidad entra a Escena}

Aunque la intersección entre arte y subalternidad ha sido ampliamente trabajada desde disciplinas como la historia del arte o la filosofía no ha sido abordada con suficiente profundidad desde la antropología. De hecho, una de las críticas que se le hace a la antropología es que se haya centrado en cómo se crea el orden desde el caos dejando de lado el campo de las transgresiones, el desorden y la violencia (Daas, 1997:279).

Si nos centramos en James C. Scott tenemos algunos apuntes interesantes:

"Queremos mostrar que ni las formas cotidianas de resistencia ni la insurrección ocasional se pueden entender sin tener en cuenta los espacios sociales cerrados en los cuales esa resistencia se alimenta y adquiere sentido. Si se hiciera con la minucia que no podemos utilizar aquí, dicho análisis esbozaría una tecnología y una práctica de resistencia, similares al análisis que hizo Foucault de la tecnología de la dominación" (Scott, 2004 :45).

Contamos con un inconveniente, la unión entre estas dos corrientes no ha sido muy prodiga especialmente, recordemos la cita de Piscator preguntándose por la falta de actitudes de la clase proletaria con respecto al teatro (Piscator,2001: 64).

Quizá uno de los primeros autores teatrales que da un giro en este sentido es Augusto Boal con sus trabajos, primero en Brasil y, posteriormente, en países de América Latina y de Europa a lo largo de su exilio.

Estos procesos suelen ser desarrollados mediante duros procesos de concientización, como han mostrado Freire (2007) y Boal (1982) en el desarrollo de sus prácticas educativas dentro del campo de la alfabetización y el teatro respectivamente.

Dentro de la corriente de la subalternidad, Guha ha sido el autor que más se ha adentrado en este terreno al cual ha estudiado la conciencia campesina desde sus métodos de insurrección (Chatterjee, 1997: 199). El interesante añadido al campo que proponemos consiste en visibilizar cómo muchos métodos de resistencia cambian las armas por sus cuerpos y sus conciencias, y cómo actos subversivos clásicos, véase manifestación o huelga, cambia por otro tipo de acciones como son las performances. Acciones éstas a las que se llegan a través de un proceso en el que el individuo se transforma.

En definitiva, son subalternos que se enfrentan al orden hegemónico desde un trabajo que se puede analizar desde muchos puntos de vista:

A. Desde la construcción de un discurso subalterno elaborado mediante el referente faro o a través del colectivo. 
B. Desde los usos, con un determinado fin, de los capitales corporales desarrollados durante el entrenamiento teatral.

C. Desde el manejo de la estructura de sentimientos, la unión de cuerpo y mente, es decir, un manejo desde la praxis teatral. Entendiendo así el conocimiento como una relación simbiótica entre la inteligencia discursiva lógica, la inteligencia corporal y la emotiva.

D. Desde el estudio de la significación de la acción ejecutada.

E. Desde el manejo no sólo del acto realizativo sino del acto perlocucionario (Austin, 2010:32) del mismo.

En estos procesos de concientización autores como Guha han identificado hasta 6 aspectos elementales (Chatterjee, 1997:199-200):

Negación. La conciencia negativa del campesinado se forma en oposición a la conciencia hegemónica y los signos de resistencia son el blanco de las descargas. La resistencia no se afirma por medio de su propia cultura sino de la cultura de los enemigos. Quizá por eso Guha trabaje sobre subalternos y no sobre culturas contrahegemónicas pues no dan su propia visión del mundo.

Ambigüedad. El uso de la ambigüedad en actos de insurrección hacía difícil que los poderes hegemónicos los distinguieran de a través de signos de conductas aberrantes. Tendríamos que prestar atención a la ambigüedad en términos distintos como la importancia que supone para un grupo y la no importancia que le da el otro. Reconocer algo significa darle importancia.

Modalidad. Mientras que Guha trabaja con grupos que siguen una metodología propia: arrasar, incendiar, comer y saquear.

Solidaridad. Es importante entender los cauces solidarios internos dentro de estos grupos.

Transmisión. Con qué rapidez se convoca una acción, qué códigos desarrollan y que incidencia tienen cuantitativamente.

Territorialidad. Guha se refiere a dos tipos de extensión: la marcada por el territorio del enemigo, de tipo negativo, y la marcada por el espacio étnico insurgente, de tipo positivo.

Si Augusto Boal creó una metodología que usaba el teatro como herramienta para "ensayar la revolución" nosotros lo que pretendemos rescatar es dicho proceso de ensayo para entender la subjetivación política de los agentes teatrales en dicho proceso.

Lo interesante desde el punto de vista teatral es que la disposición política no sólo cambia en un plano mental sino que se objetiva en la performance. Gracias al teatro hay un encuentro doblemente subjetivado y doblemente objetivado (Lube, 2010: 85) pues el maestro comunica una idea que el alumno tiene que objetivar desde su subjetividad, lo interesante es que no puede quedarse en la mente del alumno sino que debe hacerlo abiertamente. 
Si enteder este cambio en la disposición política es un aspecto importante dentro de la subalternidad, no menos lo es el estudio de la hegemonía, la cual ya hemos definido y que matizamos a continuación:

"[...] la concepción del mundo que se manifiesta en el arte, en el derecho, en la vida económica y en todas las manifestaciones individuales y colectivas. Ideología no es pues hegemonía para Gramsci pues la hegemonía implica siempre una actividad práctica y relaciones sociales responsables de desigualdad, así como las ideas que la justifican, regulan y explican". (Crehan, 2002: 195).

En esta línea Williams define hegemonía (Williams, 1977: 129) como un dominio que abarca la cultura y la ideología, es más la hegemonía necesita el reconocimiento de la dominación al ser un proceso total: un cuerpo de prácticas y expectativas en relación con la totalidad de la vida.

Scott se centrara más en analizar el grado de consentimiento que tienen la hegemonía porque es en este aspecto donde reside su punto débil: en el grado de consentimiento.

Tanto Williams como Scott ven en la hegemonía un todo social que no es individual y que se desarrolla en continuum, como decía Gramsci, es decir, en un proceso. Pero mientras que Williams se limita a decir que no es un proceso total, pues siempre tiene un opuesto que obliga a la hegemonía a estar siempre alerta hacia las alternativas y oposiciones que cuestionan su dominaciónsiendo las obras de arte una fuente de esta evidencia- (Williams, 1977: 135) Scott analiza la hegemonía y la divide en dos frentes: la versión fuerte y la versión débil de la hegemonía (Scott, 2002: 99).

La versión fuerte sería aquella que logra que los dominados crean firmemente en los valores de la hegemonía y justifican así su propia subordinación. La versión débil convence al dominado mediante el sentido común del dominado naturalizando su dominación.

La versión fuerte logra sus propósitos mediante el consentimiento y la débil mediante la resignación. Scott mantiene que esta última es la más convincente ya que: "no propone nada más allá de la aceptación de la inevitabilidad" (Scott, 2002: 107).

De todos modos, para Scott ninguna dominación es capaz de impedir la creación de espacios sociales independientes dentro de los cuales los subordinados puedan hablar con relativa facilidad (Scott, 2002: 112). Aunque la cuestión no reside en crear ese espacio, sino en qué se hace dentro de él. La cuestión no es tener un espacio seguro en el que hablar, sino un espacio en el cual se escape de la hegemonía, la cual está en los propios discursos de los dominados (Bourdieu, 1995: 51). Ese espacio será, en principio, un espacio subalterno y sólo con una organización eficiente y con una propuesta cultural armada podrá llegar a ser contrahegemónico pero, ¿de qué manera se reunen esas características? ¿cómo se construyen esas relaciones y esos discursos? ¿Es posible hacer eso desde un grupo de teatro? 


\section{Conclusiones}

Tenemos claro que la hegemonía no es inexpugnable pero, ¿cómo se combate? Es aquí donde el investigador comprometido del siglo XXI debe invertir todas sus fuerzas. Recordando la famosa tesis XI sobre Feuerbach de Marx: es hora de investigar para transformar, no sólo para interpretar (Marx, 1966). Pero para poder llegar a lo uno se ha de pasar por lo otro, quien no interpreta no puede transformar.

Un análisis que parta de Boal debe atender no sólo al teatro como espectáculo sino que debe centrarse en la creación de una performance, desde el ensayo, hasta la obra en si. Consideramos, además, más importante el proceso interno de creación que el producto-espectáculo final (Debord, 2009) e identificamos como elemento fundamental el proceso de cambio que opera en los individuos y que incide en sus actos o performances cotidianas.

En Boal vemos cómo construye su proceso contrahegemónico desde la conformación de una acción en escena hasta el manejo de sus capitales corporales, el manejo de discursos ocultos y el manejo interno de la información, qué estética presentan, cómo se organizan, cómo se objetiva su ideología y cómo crea los procesos de estructuración de nuevos sentimientos y por tanto de un determinado ethos y finalmente cómo forma una nueva disposición política.

Abordar un proceso teatral es como entrar en un laboratorio de subalternidad artística para entender la forma y el contenido, tanto del código teatral como de las relaciones de poder. No es sólo lo que se dice, sino cómo se dice; y no solo es luchar sino cómo luchar.

Para ilustrar mejor una parte del análisis veamos una discusión entre la que median casi 250 años de diferencia.

"Segundo: Pero si una muchedumbre reunida en la calle por una catástrofe, desplegase súbitamente, cada uno de en su forma natural, su sensibilidad, sin ponerse de acuerdo, crearían indudablemente un maravilloso espectáculo, hecho de mil pedazos preciosos para la escultura, la pintura, la música o la poesía.

Primero: es cierto, pero, ¿Podría compararse ese espectáculo con el que resultase de un inteligente acuerdo, de esa armonía introducida por el artista al trasplantarlo de la calle a la escena o al lienzo? [...] con el espectáculo teatral sucede lo que en toda sociedad bien ordenada: cada uno sacrifica parte de sus derechos en beneficio de los demás y de la armonía del todo. ¿Quién apreciará mejor la medida de este sacrificio? ¿El entusiasta? ¿El fanático? Ciertamente no. En la sociedad será el hombre justo, en el teatro el comediante de cabeza fría. Su escena de la calle es a la escena dramática como a una horda de salvajes a una asamblea de hombre civilizados" (Diderot, 1999: 55-57).

He sacado a colación este comentario pues Diderot ya está esbozando cómo sería una manifestación actuada en la cual cada uno juega su papel.

Si la acción de la manifestación fuera previamente ensayada y trabajada bajo el formato de una performance nos encontraríamos con elementos artísticos como los que mencionaba Diderot. Pero además, de la propuesta de Diderot 
rescatamos la importancia del trabajo reflexivo sobre sí mismo que cada manifestante ha de realizar para conseguir hacer de la manifestación una "obra de arte". Este proceso es lo que impregna de significado al acto al dotarle de un ethos trabajado que nos va a hablar mucho del tipo de subalternidad que se plantea.

Sería, recuperando nuevamente a Scott, cómo se pasa del sentimiento crudo al cocido (Scott 2003: 299), cómo se comparte una respuesta que se ha articulado como discurso oculto frente a otras respuestas que no se han podido, cocinar, ensayar, de modo que salen a la luz en forma de venganza y poco estructurada (ibid.: 299).

Lo que nos interesa por tanto no es sólo el acto de cruzar el Rubicón, de pasar el punto de no retorno, sino estudiar qué hace a alguien dar ese paso y cómo lo hace. Es cierto que el propio status de dominado es suficiente para rebelarse, pero como investigadores nos interesa entender cómo entra la subjetividad en escena o como diría Foucault: "Hay sublevación, es un hecho; y mediante ella es como la subjetividad (no la de los grandes hombres, sino la de cualquiera) se introduce en la historia y le da un soplo [...]. Basta que existan y que tengan contra ellas todo lo que se empeña en hacerlas callar para que tenga sentido escucharlas y buscar lo que quieren decir.". (Foucault, 1999: 206).

\section{Referencias bibliográficas}

(2001) ABELLÁN, Joan, Boal Conta Boal, Institut del Teatre, Barcelona.

(2013) ALVARADO, Iván, Los márgenes toman la escena, [En línea] http://www.revistaciencia sociales.cl/archivos/revista30/pdf/rcs30_art03.pdf

(2010) ARISTÓTELES, La Poética, Alianza, Madrid.

(2010) AUSTIN, John, Cómo hacer cosas con las palabras, Paidós Estudio, Madrid.

(2005) ALEXANDER, Jeffrey, "Pragmática cultural: un nuevo modelo de performance social", Revista colombiana de sociología, nº 172, pp. 9-67.

(2009) BARAÚNA, Tania; MOTOS, Tomás, De Freire a Boal, Ñaque, Ciudad Real.

(2005) BHARUCHA, Rustom, Theatre and the World. Performance and the Politics of Culture, Routledge, London.

(1982) BOAL, Augusto, Teatro del Oprimido. Teoría y Práctica, Nueva Imagen, México.

(2004) BOAL, Augusto, El Arco Iris del Deseo. Del Teatro experimental a la terapia, Alba, Barcelona.

(2009) BOAL, Augusto, Teatro del oprimido, Alba Editorial, Barcelona. 
(1977) BOURDIEU, Pierre, "La production de la croyanze. Contribution á une éconimie des biens symboliques", Actes de la Recherche en Sciences Sociales, (13 febrero 1977). pp 3-43.

(1995) BOURDIEU, Pierre y WACQUANT, Louic, Respuestas por una antropología reflexiva, Grijalbo, México.

(2007) BOURDIEU, Pierre, Razones prácticas, Anagrama, Barcelona.

(1972) BRECHT, Bertolt, La Política en el Teatro, Alfa, Buenos Aires.

(2004) BRECHT, Bertolt, Escritos sobre Teatro, Alba Editorial, Barcelona.

(1998) BUTLER, Judit. "Actos performativos y constitución del género: un ensayo sobre fenomenología y teoría feminista", Debate feminista, 18. pp 296314.

(1997) CHATTERJE, Partha, "La Nación y sus campesinos". En Silvia Rivera y Rossana Barragán (Dir.), Debates Post Coloniales: Una introducción a los estudios de subalternidad, Sierpe, La Paz. pp 195-210.

(2008) COLLINS, Randall, Violence. A micro sociological theory, Princeton University Press.

(2002) CREHAN, Kate, Gramsci. Cultura y antropología, Bellaterra, Barcelona.

(1997) DAAS, Verena, "La Subalternidad como perspectiva", En Silvia Rivera y Rossana Barragán (Dir.), Debates Post Coloniales: Una introducción a los estudios de subalternidad, Sierpe, La Paz. pp 279-292.

(1999) DIDEROT, Denis, La Paradoja del Comediante, www.elaleph.com. Consultado: 22.Octubre.2010.

(2011) FISCHER-LIECHTE, Erika, Estética de lo performativo, Abada Editores, Madrid.

(1994) FOUCAULT, Michel, "EL ANTI EDIPO. Introducción a la vida nofascista",

ZonaErógena(18)(1994).publiaciónelectrónica:http://www.congresoed.org/wpcontent/uploads/2014/10/michel-foucault-prologo-a-antiedipo-1.pdf. Consultado 14 marzo 2015.

(1999) FOUCAULT, Michel, Ética, Estética y Hermenéutica, Ángel Gabilondo (compilación), Paidós Básica, Barcelona. Pág 139- 233.

(2001) FOUCAULT, Michel, La hermenéutica del sujeto, Akal, Madrid.

(2010) FOUCAULT, Michel, Tecnologías del yo. Y otros textos afines, Paidós, Barcelona.

(2007) FREIRE, Paulo, Pedagogía del Oprimido, Siglo XXI, Madrid.

(1976) GRAMSCI, Antonio, Introducción a la Filosofía de la praxis, Península; Barcelona.

(1981) GRAMSCI, Antonio, Cuadernos de la cárcel, (Valentino Gerratana Dir.) Vol I, ERA, México.

(2010) LUBE, Menara, “La Favela presente: Risas, llantos y la transnacionalización de la memoria de los líderes brasileños de la capoeira en 
Madrid". En: Cultura y política ¿hacia una democracia cultural?. III training de seminar de jóvenes investigadores en Dinámicas Interculturales, Cidob, Barcelona.

(1966) MARX, Karl, XI Tesis sobre Feuerbach, Progreso, Moscú.

(2009) MÉNDEZ, Lourdes, Antropología Del Campo Artístico: Del Arte primitivo al Contemporáneo, Síntesis, Madrid.

(2001) RUBIO, Miguel, Notas sobre teatro, (Ramos Luis Ed.), Grupo Cultural Yuyachkani, Lima-Minnesota.

(2013) SÁNCHEZ PRIETO, Juan María, “Los desafíos del 'giro performativo': el modelo de Alexander y la pervivencia de Turner". En Oncina, Faustino y Elena Cantarino (Dir.), Giros narrativos e historias del saber, Madrid, Plaza y Valdés. pp. 77-110.

(1989) SCHECHNER, Richard, Between theater \& anthropology, Philadelphia, University of Pennsylvania Press.

(1990) SCHECHNER, Richard, "El training en una perspectiva intercultural". En Eugenio Barba y Nicolás Savarese (Dir.), El arte secreto del actor. Diccionario de antropología teatral, Escenología, A. C, México. pp 330-331.

(2000) SCHECHNER, Richard, Performance. Teorías y prácticas Interculturales, Libros de Rojas, Buenos Aires.

(2000) SCOTT, James, Los Dominados y el arte de la resistencia. Discursos Ocultos, Era, México.

(2003) SCOTT, James, Los dominados y el arte de la resistencia, Txalaparta, Tafalla.

(1982) TURNER, Victor, From Ritual to Theatre. The man seriousness of play, PAJ Books, New York.

(1988) TURNER, Victor, El Proceso Ritual, Taurus, Madrid.

(2013) VICENTE de, César, La escena constituyente. Teoría y práctica del teatro político, ed Centro de Documentación Crítica, Madrid.

(2004) WACQUANT, Loic, Entre las Cuerdas. Cuadernos de un aprendiz de boxeo, Alianza, Madrid.

(1995) WACQUANT, Loic, "Pugs at work: Bodily Capital and Bodily Labour among Professional Boxers", Body \& Society, Vol 1, No. 1, Sage publications, California, pp. $65-93$.

(1977) WILLIAMS, Raymond, Marxismo y Literatura, Península, Barcelona. 